\title{
To Study the Rise in Satisfaction Level of People due to E- Governance Initiative by Government of Punjab-A Case Study of Excise and Taxation Department
}

\author{
Sheikh Zahoor Sarwar, Saif Ur Rehman, Muhammad Umar Farooq, \\ Rozeia Mustafa, Asif Irfan \\ Institute of Business \& Management UET Lahore Pakistan
}

\begin{abstract}
Purpose -The main objective of doing this research is to study the rise in satisfaction level of people of Punjab due to E-governance initiatives of the government of Punjab.

Design/methodology/approach - E-governance was introduced in the province with the help of various Information Systems. We identified various aspects of these e-systems affecting customer satisfaction like ease of use and efficiency. We made questionnaire to find out these factors and got information from customers via interviews and finally analyzed outcome to get results from the statistics analysis.

Findings - Results indicated a strong relationship of customer satisfaction with the e-governance initiatives and this relationship indicated that by enhancement in ease of use and efficiency of these e-systems customer satisfaction will certainly rise.

Research limitations - Only one department was selected as a case study in this research, however the results will be easy to encompass the provincial level initiatives, since all of the departments are getting same level of automation and information policy.

Practical implications - Our research has exposed that effective deployment of information technology can improve customer satisfaction of people of Punjab. The strong positive relationship between various factors of customer satisfaction indicates that there is a possibility of rise in customer satisfaction with concentrated efforts.

Originality/value - There has been no native research ever done on these e-systems to indicate their effectiveness, hence now it was time that decisions are made on basis of informed and organized research based statistics.
\end{abstract}

Keywords - Customer satisfaction, efficiency, ease of use, e-governance, Excise and Taxation department, government of the Punjab.

\section{Introduction}

E-Governance is the new Good governance. (Sarfraz, 2007).

According to White, Harrison and Turner (2010) more and more academic literature and studies of related systems has started to show that there has been a dramatic and positive effect of internet on customers in numerous ways.

There is an increasing role of online services in lives of ordinary people of every society worldwide.

E-governance is as defined by Backus in 2001 as "interaction among government, citizen, and businesses has simplified and improved with electronic means and also improved the democratic, government and business aspects of Governance"

In the year 2004, a huge amount of money was dedicated in the provincial budget to start various projects to enhance e-culture in the province of Punjab. Most of these projects completed successfully and managed to deliver a lot of good for the people in the province. However due to economic recession in the country, deliberation on spending funds in these pricey projects has somewhat shaken. There is a need that some sort of in-depth analysis of these projects may be taken both in terms of monetary and social benefits in order to measure their outcome for prospect funding in the future.

We therefore decided to analyze the benefits due to the e-governance initiatives and one of the major beneficial factors was to measure rise in customer satisfaction due to these projects. Here it is worth mentioning that the prime purpose in implementation of these reforms lied within the aim that in doing so there will be an increase in the facilitation to public and government (ease in paying taxes and manageability of the tax records) at the same time that will give rise to the tax net in the province. 


\section{Literature Review}

E-governance as defined by Sarfaraz (2007) "the use of information technology to support government operations, engage citizens, and provide government services."

In our research we decided to evaluate e-governance initiatives in form of development projects started in the province by government of the Punjab. This evaluation is on basis of their role in betterment of social lives of the public. According to Natisa Simic 2011, development projects represent investments in the development of a country's social and economic infrastructure, and differ from standard industrial or economic projects in terms of their significance for the country.

Customer satisfaction created due to these e-governance projects was one of the social indicators; it was related to change in lives of public with provision of various easy to use and efficient means of interaction with the government. Kotler (2000, p.36) defined satisfaction as "the satisfaction is an individual's feelings of delight or displeasure resulting from evaluating a product's perceived performance and in relation to his or her expectations from the service".

Talking about the customer satisfaction, Customer will be satisfied if the service performance meet or exceed the customer hope if it is less than customer expectation then customer will be dissatisfied. (Sriyam, 2010)

Our research was based upon determining the rise in satisfaction level and it was necessary to analyze the present situation and compare it with the one before implementation of the e-governance in the province.

According to Dinsdale and Marsden, 1999, two key factors significant for assessment of customer satisfaction are the number of contacts required and the time required in completing the service episode.

Perception, assessment and psychological reactions to experience the product are a combined result of customer satisfaction Yi (1990). The role of customer satisfaction in such development projects is key towards their evaluation since they are run from tax payer's money and they are prime stake holders of such investment therefore they must be one to evaluate these services as per their perceptions.

Another factor for the measurement of these initiatives is as customer satisfaction is increased the customer loyalty which leads to profitability of organization. (Heskett et al, 1994. discussed in Storbacka et al., 1994). Profitability in this instance means that the rise in satisfaction among public will help increase tax net associated directly with increase in public trust in services provided by the government.

A positive word of mouth will help public recommend the services to other customers and this process will help at first hand in gaining trust of the masses towards tax reforms and its positive usage towards their betterment. Secondly another aspect of these initiatives is the manageability of taxes collected and eases in reporting this volume in financial statements for informed decision making. Thirdly an ease in management and analysis of data from these initiatives will help isolate grey areas from the taxation system and focus particularly on them to increase tax efficiency.

Increasing e-commerce utilization in private sector has made people aware of various ways to interact with each other and with different forms of everyday businesses; this has raised their expectations from public sector.

E-governance systems involve customers into the process by self service modules, like self assessment of taxation, making online payment of their dues, etc as Agarwal, Shah \& Wadhwa, (2010) described that customer orientation and involvement are playing a important role for success stories of businesses across the world which means that governments cannot possibly ignore their people who are essentially the stake holders of the government (public) services.

Reisig \& Chandek (2001) endorsed the fact that various customers have diverse expectations, which are developed on basis of their knowledge with respect to a product or service. E-governance systems have to fulfill varying expectations, they need to be simple and comprehensive at the same time, to focus not only those who are well versed with Information technology, but also provide sufficient help and assistance to those who are not apt in it. To address this issue we decided to investigate the e-governance systems for two different aspects, first for the ease of use and secondly for efficiency, ease of use will help the novice users and efficiency will measure the satisfaction of those customers who are already experienced with such systems. According to Santos (2003), Fassnacht and Koese (2006), T.Ramayah and Joshua Ignatius, (2010) ease of use and efficiency are a reliable and tested scale for evaluation of any e-service project for its customer satisfaction in a public sector organization. One issue that lies with the public sector initiatives, not only in information technology but in anywhere else in the same way is that public in general is reluctant towards adoption of these, perhaps the inertia carried from the previous factor and the disturbance of comfort zone of the people is what keeps people from adoption. Heaney (2007) discovered that to determine the process of e-service adoption, ease of use and trust are most serious factors. Another factor that is required after adoption of any new system is sticking to it and being involved into a positive word of mouth to encourage other users about it, a loyal customer will attract other customers and this can only happen if he is satisfied with the system as Ribbink et al. (2004) pointed out that factor dimensions like ease of use, responsiveness, and customization is essentially related to e-loyalty, via 
satisfaction. User satisfaction is very important factor to get the success of web based system. Customer will continue to use of the system if he will satisfied with online services. (Al-Kasasbeh, Dasgupta \& AL-Faouri, 2011)

\subsection{Customer Satisfaction}

Hernon \&Whitwan (2001) declared customer satisfaction being a gauge of service delivery in the eye of a customer, in the same context Oliver defines satisfaction is a consumer's sense that consumption provides results against a standard of delight against dissatisfied.

Customer satisfaction is associated with 'value' and is based, theoretically, on the amalgamation of service quality traits with such traits as price. (Athanassopoulos, 2000, p. 192)

\subsection{Ease of Use}

Ease of use perceived by a customer is directly related to services being offered and refers to the extent to which a person believes using the technology will be free of effort. In an e-commerce setting, ease of use has been confirmed as a key factor leading to satisfaction (Devaraj el al. 2002). Studies about the online services prove that perceived control of users against any service encourages its usage and loyalty, resulting in more satisfied customers (Lee and Allaway 2002)

On the internet, ease of use is considered to be much significant factors to customers (Eighmey and McCord 1998; Fram and Grady 1995).

Ease of use is the ability of a customer to find information or enact a transaction with the least amount of effort. ( Collier \& Beinstock, 2006)

Perceived Ease of Use is a degree to which any user expects that the online system will be used effortlessly." (Davis, 1989)

Customer Perceived usefulness and ease of use of a system can provide valuable information to the user in his assessment about online quality of service of an e-governance system. (Davis, 1989)

\subsection{Efficiency}

Efficiency is related to the internal strengths of the system, it defines the limits to which the system can be tapped for benefits. It is the key factor for an online system as Santos (2003), Fassnacht and Koese (2006), T.Ramayah and Joshua Ignatius, (2010) declared efficiency as a reliable and tested scale for evaluation of any eservice project for its customer satisfaction. However experienced customers who have achieved a particular level to understand the operation of an information system become less concerned with efficiency and turn their attention to other requirements, (Massey, Khatri \& Weiss 2008).

\section{E-Government Framework}

The essential architecture of the e-gateway consists of a set of web-based applications for citizen services and back office systems, together with centralized shared infrastructure including data center, provincewide connectivity, licensed software, and e-mail. The e-gateway citizen contact center provides convenient access to citizens utilizing call centers, kiosks, web-portal, and mobile phones.

The Punjab e-gateway implementation plan is based on a multi-pronged and phased approach, with initiatives for development of:

a) Shared infrastructure and services

b) Web presence and related citizen services

c) Back office systems and integration of legacy systems

d) Human resources

e) Necessary regulatory and legal framework

The multi-pronged and phased approach is consistent with e-government strategies adopted by countries with highly successful e-government programs such as Korea (ranked number 6 on United Nation's egovernment readiness), Singapore (number 23), and Egypt (moved from 140 to 79 between 2005 to 2008). Egypt's ICT strategy over 2003-2010 was multi-pronged with three main pillars including R\&D and education, internet access, and appropriate regulatory environment. India's Andhra Pradesh strategy included four key components (BEST): bandwidth, education, smart government, and twinning with the private sector.

The Korean strategy was multi-phased with the first ten years (1987-96) spent in setting up the basic connectivity infrastructure and setting up the data bases on citizen registration papers, property titles, and vehicle registration. In the second phase (1997-2000) connectivity was upgraded to interconnect 144 districts, websites were set up, systems were developed for government procurement and financial management, and the necessary legislative framework was established. Korea attributes the remarkable success of the e-government effort to the president who personally monitored the project through weekly briefings. The e-government IT unit 
provided a facilitating role; while the beneficiary department ensured that the new systems were implemented and utilized.

This research is centered towards finding out the benefits of implementation of MIS systems in the province and to help the people of the province which are customers of the government of Punjab in its various functions.

While going through different studies already performed on the topic and careful review of information and literature we developed a problem statement that goes:-

"To study the rise in satisfaction level of people due to e-governance initiatives by government of the Punjab-A case study of Excise and Taxation Department"

\section{Research Objective}

The intention behind this study was to assess the effects of introduction of various MIS systems by public sector in Punjab province. We tried to evaluate the MIS systems of Excise and Taxation department under predefined variables. The research was done at both levels, at first the benefits were quantified against pre established quality indicators and then we reviewed various aspects of information systems that may increase the quality of service delivery to its stake holders.

\section{Methodology of Research}

In this research we carried out surveys and conducted interviews to recognize effects of e-governance initiatives on public satisfaction at different offices of the Excise and Taxation Department, Government of Punjab. For the assessment of effects of pre and post implementation of computerization in the department, criteria were established to determine relevant weight-age carried by different aspects of enhancement in public satisfaction. The study also investigated the social, political, ethical, economical and business benefits of computerization on the department. The same results can now be used to perceive a same model to follow for the other departments needing computerization.

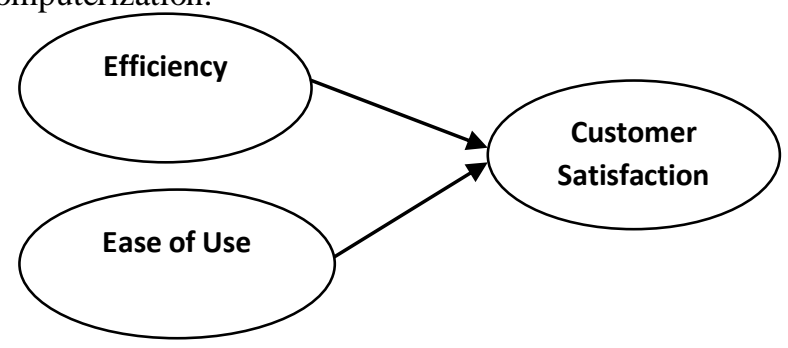

\section{Data Sampling and Data collection}

There are 4.8 million vehicles registered with Excise and Taxation Department till to-date in the province of Punjab, this is a huge population therefore random sampling technique was used to fill the questionnaire for the research. A total of 380 respondents were interviewed out of which 345 questionnaires were declared to be complete and fit for analysis.

\section{Data Recording}

The data was recorded by the researchers on pre-developed questionnaire forms that were adopted from the previous researches done by people for customer satisfaction investigation. There were total 22 Questions which were designed to measure three different variables.

We asked our respondents to give the answer of questions on a Likert scale of five-points, where $1=$ Strongly Disagree, 2= Disagree, 3= neutral, 4=Agree and 5= Strongly Agree .

\section{Respondent Characteristics}

The respondents of our research consisted of customers of Excise and Taxation Department who visited various tax collection centers of the department, they included both females and male, the data gathering was done on two different locations of the department.

\subsection{Reliability Test}

\section{Data Analysis and Results}

The basic purpose of reliability test is to measure the internal consistency of questionnaire. Reliability tests are measured by computing the value of Cronbach Alpha and it is considered to be ideally when its value equal to 0.7 and greater (Pallant, 2007).

In below Table 1, we can see that the value of Cronbach is $0.901,0.818$ and 0.827 of all three items i.e. ease of use, efficiency of MIS system and customer satisfaction respectively. All the values of Cronbach Alpha are greater than the acceptable level of reliability $(\alpha \geq 0.70)$ (Sekaran and Bougie, 2010). 
Table 1: Results of Reliability Test

\begin{tabular}{|l|l|l|l|}
\hline Alpha Cronbach & $\mathbf{0 . 9 0 1}$ & $\mathbf{0 . 8 1 8}$ & $\mathbf{0 . 8 2 7}$ \\
\hline Items & $\begin{array}{l}\text { Ease of Use/Access of } \\
\text { MIS System }\end{array}$ & $\begin{array}{l}\text { Efficiency of MIS } \\
\text { System }\end{array}$ & $\begin{array}{l}\text { Customer } \\
\text { Satisfaction }\end{array}$ \\
\hline
\end{tabular}

\subsection{Correlation Analysis}

Pearson correlation coefficient is to measure the liner correlation between the two variables. In below Table 2, we can see that the value of correlation coefficient of all variables has ranged from 0.339 to 0.693 and significant at $\mathrm{p}<0.01$, which also indicates the strength of relationship, As per Pallant, (2001) correlation between the predictor and dependent variable should be less than 0.70 and if the value is greater than the 0.7 then we need to remove the variables.

Table 2: Correlation Results Correlations

\begin{tabular}{|ll|r|r|r|}
\hline & & $\begin{array}{c}\text { Ease of } \\
\text { Use/Access of } \\
\text { MIS System }\end{array}$ & $\begin{array}{c}\text { Efficiency of } \\
\text { MIS System }\end{array}$ & $\begin{array}{c}\text { Customer } \\
\text { Satisfaction }\end{array}$ \\
\hline $\begin{array}{ll}\text { Ease of Use/Access of MIS } \\
\text { System }\end{array}$ & $\begin{array}{r}\text { Pearson Correlation } \\
\text { Sig. (2-tailed) }\end{array}$ & .339 & $.403^{* * *}$ \\
& $\mathrm{~N}$ & 345 & .000 & .000 \\
& Pearson Correlation & $.339^{* * *}$ & 345 & 345 \\
\hline & Sig. (2-tailed) & .000 & 1 & $.693^{* *}$ \\
& $\mathrm{~N}$ & 345 & .000 \\
& Pearson Correlation & $.403^{* *}$ & $.693^{* *}$ & 345 \\
\hline & Sig. (2-tailed) & .000 & .000 & 1 \\
& $\mathrm{~N}$ & 345 & 345 & 345 \\
\hline
\end{tabular}

\subsection{Regression Analysis}

The regression analysis was also carried out on this study for testing of hypothesis. Results showed that there was significant influence for the independent variables i.e. ease of use and efficiency in explaining customer satisfaction as follows; Ease of use (Beta $=0.190, \mathrm{P}<0.001)$, and Efficiency $($ Beta $=0.628, \mathrm{P}<0.001)$. Thus, a hypothesis was supported. Table 3 shows the results of regression analysis.

Table 3

Coefficients $^{\mathrm{a}}$

\begin{tabular}{|c|c|c|c|c|c|c|}
\hline \multirow{2}{*}{\multicolumn{2}{|c|}{ Model }} & \multicolumn{2}{|c|}{ Unstandardized Coefficients } & \multirow{2}{*}{$\begin{array}{c}\begin{array}{c}\text { Standardized } \\
\text { Coefficients }\end{array} \\
\text { Beta }\end{array}$} & \multirow[b]{2}{*}{$\mathrm{t}$} & \multirow[b]{2}{*}{ Sig. } \\
\hline & & B & Std. Error & & & \\
\hline \multirow[t]{3}{*}{1} & (Constant) & 1.824 & .125 & & 14.638 & .000 \\
\hline & $\begin{array}{l}\text { Ease of Use/Access of MIS } \\
\text { System }\end{array}$ & .099 & .021 & .190 & 4.719 & .000 \\
\hline & Efficiency & .432 & .028 & .628 & 15.646 & .000 \\
\hline
\end{tabular}

a. Dependent Variable: Customer Satisfaction

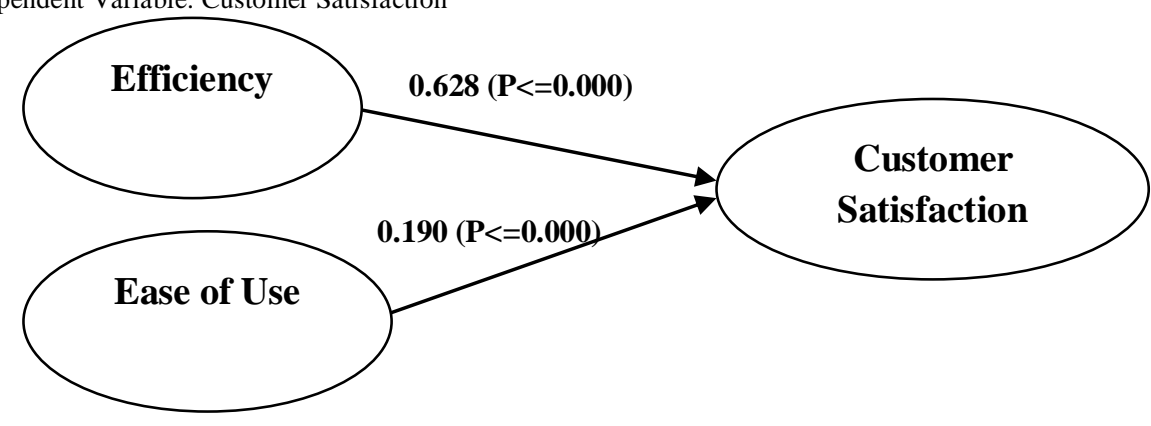

It was evident that there is contribution of both independent variables Efficiency and Ease of Use of MIS System towards rise in Customer satisfaction, however there is stronger relationship between the Customer Satisfaction and Efficiency of the MIS system (Beta $=0.628)$ at a significance level of $(\mathrm{P}<0.000)$, this higher 
value of Beta shows that out of two variables Efficiency has more effect on Customer satisfaction than Ease of use of MIS system. Hence taking steps to improve Efficiency of MIS Systems will be more fruitful towards rise in Customer satisfaction from e-governance initiatives of Government of the Punjab and investment in Ease of Use/Access will also support to increase the customer satisfaction.

\subsection{Linear Equation}

Customer Satisfaction $=1.824+(0.099) \times$ Ease of Use $+(0.432)$ x Efficiency of MIS System

\section{Conclusion}

The major purpose of this study was to discover the impact of introduction of e-governance in the province of Punjab on customer satisfaction. The obtained results exposed that higher the perceived ease of use and efficiency of an MIS system, greater is the satisfaction among customers. Therefore, government should focus on integration of these factors while designing any of the MIS systems being implemented in the province and also work to enhance these two factors to gather greater customer acceptability towards online e-governance systems in the province. Besides that, government should invest on development of infrastructure, training and development of e-culture in the province to harvest more value from its e-governance systems. There has been various trainings and skill development activities being taken in the province in form of on job trainings, seminars, workshops and certifications for employees of government, our research will help define the course of action and even the very areas to be focused while developing the course and training contents. This will certainly help in getting more value from these activities. The other end of the system the customers are ordinary public, our research has suggested that e-governance cannot possibly achieved without their active participation, no doubt with the advancement in private sector the common public has become quite conversant with the computers and online systems, however a lot of our population is still not aware of these, and this research will suggest what type of qualities a system should have to make it so easy and understandable to even non-educated or less-educated people of the province. This research revealed that the customer perceived satisfaction relies on their knowledge of the systems and one way of doing it can be trainings on basic as well as intermediate levels to masses through media campaign and locality level awareness campaigns. Another way is to provide onsite guidance/interactive training system that can help people learn more about these systems. As the e-culture is increasing drastically in business environment of private sector nowadays, the need to enhance satisfaction in egovernance will also increase. Our research shows that if more people are e-ready the fruit of e-culture will not only be reaped by the government but also by anyone doing business in the province, this idea will help establish public private partnership to develop integrated systems, train more and more people and provide much needed financial resources for the projects of e-governance and when they will spend for the common cause and with collaboration, more trust will be exhibited by the customers in this regard which will help convert this into an opportunity for future development in the province.

Based on this research the possible strengths and benefits which we can reap from the new concept of e-governance should be realized by the government and steps should be taken to find out new opportunities and effectively respond threats in this field. More emphasis on e-governance and timely decisions will help lay a ground upon which future development will be based.

\footnotetext{
References

[1]. Albert Caruana (2002). Service Loyality-The effects of service quality and the mediating role of customer satisfaction, European Journal of Marketing Vol36 7/8.

[2]. Anand Agrawal1, Pragya Shah \& Varun Wadhwa (2010), EGOSQ - Users' Assessment of e-Governance Online-Services: A Quality Measurement Instrumentation. Available at www.irma-international.org/chapter/assessing-governance-online-servicequality/8981/

[3]. Anderson, H. \& Jacobsen P. N., (2000), Creating Loyalty: Its Strategic Importance in Your Customer Strategy. S. A. Brown, ed., Customer Relationship Management, Ontario, John Wiley, pp. 55-67.

[4]. Anne P. Massey Vijay Khatri \& Mitzi M. Montoya (2008). Customer characteristics and usability requirements. Proceedings of the 41st Hawaii International Conference on System Sciences.

[5]. Backus, Michiel (2001). E-governance in developing countries, IICD Research Brief No1, retrieved September 21, 2011. Available at:http://www.ftpiicd.org/files/research/briefs/brief1.doc.

[6]. Collier \& Beinstock, (2006) Measuring Service Quality in E-Retailing, Journal of Service Research; 8; 260.

[7]. Darin W. White, Joe C. Harrison Sam Turner (2010). Does Customer engagement with internet based services influence adoption of other new products. Canadian Journal of Administrative Sciences (Published online 29 March 2010)

[8]. Devaraj, S., M. Fan, R. Kohli (2002). Antecedents of B2C channel satisfaction and preference: validating e-commerce metrics. Information Systems Research, 13(3), 316-333.

[9]. Eugene W. Anderson August (1998). Customer satisfaction and word of mouth. Journal of Service Research Vol1.

[10]. Eugene W. Anderson Claus Fornell, and Donald R. Lehmann (1994). Customer satisfaction, market share, and profitability findings. Sweden Journal of Marketing Vol58.

[11]. George Athanasopoulos, Heather M. Anderson, Farshid Vahid (2001) Department of Econometrics and Business Statistics, Monash University.

[12]. Joel E. Collier, Carol C. Bienstock (2006). Measuring service quality in e-retailing. Journal of Service Research; $8 ; 260$

[13]. Jungki Lee, Arthur Allaway, (2002) Effects of personal control on adoption of self-service technology innovations", Journal of Services Marketing, Vol. 16 Iss: 6, pp.553 - 572
} 
[14]. Kotler, P., (2000). Marketing Management. 10th Ed., New Jersey, Prentice-Hall.

[15]. Lee and Allaway (2002). Consumers channels and communication: online and offline communication in service consumption. Journal Interacting with Computers Volume 19 Issue 1.

[16]. Mohammed Mufaddy Al-Kasasbeh1, Subhasish Dasgupta and Abeer Hmoud AL-Faouri (2011). Factors affecting e-service satisfaction. IBIMA publishing Communications of the IBIMA http://www.ibimapublishing.com/journals/CIBI A/cibima.html Vol. 2011, Article ID 547937, DOI: 10.5171/2011.547937

[17]. Pallent, Julie. 2007. SPSS Survival Manual: A Step by Step Guide to Data Analysis using SPSS for Windows. England: McGraw.

[18]. Ribbink, D., Van Riel, A. C. R., Liljander, V. \& Treukens,. (2004). "Comfort your Online Customer: Quality, Trust and Loyalty on the Internet," Managing Service Quality, 14 (6): 446-456.

[19]. R. L. Oliver (1999). Whence consumer loyalty. Journal of Marketing 63, 33e44

[20]. Ronald T Rust, Anthony J Zahorak Owen (1993). Graduate School of Management Vanderbilt University Nashuvile Tennessee, Journal of Retail Vol.69. No.2

[21]. Sarfaraz, H (2007). E-Governance: A case for good governance in Pakistan. Available at SSRN: http://ssrn.com/abstract=1415689 or DOI:10.2139/SSRN.1415689

[22]. Sejin Ha \& Leslie Stoel (2008). Consumer e-shopping acceptance: Antecedents in a technology acceptance model. Journal of Business Research.

[23]. Vangelis Souitaris and George Balabanis (2007). Tailoring online retail strategies to increase customer satisfaction and loyalty. Long Range Planning Volume 40, Issue 2, April 2007, Pages 244-261

[24]. Wahab, S., Al-Momani, K. \& Noor, A. M. (2010). The Relationship between Eservice Quality and Ease of Use on Customer Relationship Management (CRM) Performance: An Empirical Investigation in Jordan Mobile Phone Services. Journal of Internet Banking and Commerce, 15(1): 1-15.

[25]. Yu \& Fang (2009) Measuring the post-adoption customer perception of mobile banking. Services Cyber Psychology \& Behavior Volume 12, No.1 